\title{
The reporting of sensitive behavior among adolescents: A methodological experiment in Kenya
}

\author{
Barbara Mensch \\ Population Council \\ Paul C. Hewett \\ Population Council \\ Annabel Erulkar \\ Population Council
}

Follow this and additional works at: https://knowledgecommons.popcouncil.org/departments_sbsr-pgy

Part of the Demography, Population, and Ecology Commons, Family, Life Course, and Society Commons, International Public Health Commons, and the Women's Health Commons How does access to this work benefit you? Let us know!

\section{Recommended Citation}

Mensch, Barbara, Paul C. Hewett, and Annabel Erulkar. 2001. "The reporting of sensitive behavior among adolescents: A methodological experiment in Kenya," Policy Research Division Working Paper no. 151. New York: Population Council. Version of record: https://doi.org/10.1353/dem.2003.0017 


\section{The Reporting of Sensitive Behavior Among Adolescents: A Methodological Experiment in Kenya}

Barbara S. Mensch

Paul C. Hewett

Annabel Erulkar 


\title{
The Reporting of Sensitive Behavior Among Adolescents: A Methodological Experiment in Kenya
}

\author{
Barbara S. Mensch \\ Paul C. Hewett \\ Annabel Erulkar
}

Barbara S. Mensch is Senior Associate and Paul C. Hewett is Research Associate, Population Council, New York. Annabel Erulkar is Staff Program Associate, Population Council, Kenya. 


\begin{abstract}
This paper assesses whether audio computer-assisted self-interviewing (audio-CASI), a technique designed in the United States to collect data on sensitive behaviors, is a feasible method of survey data collection in a developing-country setting and whether it produces more valid reporting of sexual activity and related behaviors than traditional survey methods. The analysis is based on interviews with nearly 4,400 unmarried adolescents aged 15-21 in Nyeri, a rural district of Kenya that was selected because previous research had indicated a wide discrepancy in the reporting of premarital sexual behavior between boys and girls. The study was based on a quasi-experimental design in which respondents were randomly allocated to one of three interviewing modes-face-to-face interviews, paper and pencil selfadministered interviews, and audio-CASI — with the presupposition that increased privacy would elicit more reliable responses. The interview context was found to have a substantial effect on responses to sensitive questions about sexual and other risky behaviors among young people. Results indicate substantial and significant differences in reported rates of premarital sex across interview modes. For boys, who we suspect exaggerate sexual experience in face-to-face-interviews, the effect is in the expected direction, with a 23 percent drop in reported sexual activity in the audio-CASI mode. For girls, who we speculate underreport sexual activity when interviewed face-to-face, there is also a large difference by mode, but the effect is not in the hypothesized direction, with respondents reporting twice as much sexual activity in the interviewer mode as in the audio-CASI mode. While the audio-CASI technology performed well, with minimal mechanical problems, and while respondents were able to complete the survey with limited training, some members of the community reacted adversely to the survey, especially to the use of the computer. We consider whether this may have had an effect on the response patterns of adolescents.
\end{abstract}

This material may not be reproduced without written permission from the authors. 
The AIDS pandemic has emphasized the need to gather comprehensive data on sexual behavior from large population-based samples. As Dare and Cleland (1994: 93) argue, "The contribution of structured interview surveys to the monitoring of changes in risk behavior is a crucial issue for the evaluation of HIV control programs." In sub-Saharan Africa, where the major route of transmission is through heterosexual intercourse and where rates of infection among young people, particularly adolescent girls, are high, it is critical to collect accurate information on sexual activity before marriage (UNAIDS 1998; UNAIDS and WHO 1998). Inaccurate reporting of sexual activity and of other sensitive behaviors such as pregnancy, abortion, and sexually transmitted infections (STIs) not only undermines social science analyses that attempt to document and explain the behaviors, but also compromises program evaluations that attempt to determine whether interventions designed to improve adolescent reproductive health are effective.

Indeed, inaccurate reports of sexual behavior are likely to provide a misleading picture of HIV/STI risk among young people in sub-Saharan Africa. Not only do we not know who is having sex and under what circumstances, but our estimates of condom use are apt to be seriously biased. Unmarried girls who are willing to acknowledge that they are sexually active may constitute a selective sample of those who have had intercourse. It seems plausible that girls who are comfortable reporting sexual activity would be more inclined to use condoms since "one of the barriers to adolescent girls' contraceptive use is embarrassment and even guilt about their sexual activity" (Mensch, Bruce, and Greene 1998: 55). If so, surveys may overestimate condom use among unmarried girls who report being sexually active.

\section{The Reporting of Premarital SeX in SUB-SAHARAN AFRICA}

Researchers working in the United States and Europe have long been skeptical about the quality of the survey data they collect on premarital sexual activity, abortion, and other sensitive, illegal, or potentially risky behaviors (see Jones and Forrest 1992; Mensch and Kandel 1988; Dare and Cleland 1994; Fenton et al. 2001). However, those who have conducted adolescent surveys in sub-Saharan Africa are less likely to acknowledge that reporting of these behaviors may be suspect. ${ }^{1}$ While considerable re- 
search exists on adolescent sexual activity in sub-Saharan Africa (see, for example, Kane et al. 1993; Kiragu and Zabin 1993, 1995; Amazigo et al. 1997; Ajayi et al. 1991; Boohene et al. 1991; Görgen et al. 1998; Matasha et al. 1998; Population Reference Bureau 2001), investigators rarely question the reliability and validity of the data collected. Yet, as observed in Table 1, these published studies reveal not only strikingly different levels of premarital sex between boys and girls in virtually all countries, but also, more significantly, varying levels for each sex across countries that cannot be easily explained.

The range in sexual experience across countries is so wide that it raises questions about the accuracy of reporting. The finding of substantial differences in reported levels of sexual activity among girls in individual country studies is duplicated in analyses of never-married young women based on Demographic and Health Survey (DHS) data where the issue of comparability of questionnaires, interviewing techniques, and sam-

Table 1 Reporting of premarital sexual experience among adolescents in six subSaharan African countries, by survey characteristics

\begin{tabular}{|c|c|c|c|c|c|c|c|}
\hline \multirow[b]{2}{*}{ Country } & \multirow[b]{2}{*}{ Authors } & \multirow{2}{*}{$\begin{array}{c}\text { Year of } \\
\text { data } \\
\text { collection }\end{array}$} & \multirow{2}{*}{$\begin{array}{c}\text { Sample } \\
\text { size }\end{array}$} & \multirow[b]{2}{*}{ Location } & \multirow{2}{*}{$\begin{array}{l}\text { Ages of } \\
\text { respondents }\end{array}$} & \multicolumn{2}{|c|}{$\begin{array}{c}\begin{array}{c}\text { Percent } \\
\text { reporting } \\
\text { premarital sex }\end{array} \\
\end{array}$} \\
\hline & & & & & & Females & Males \\
\hline Gambia & $\begin{array}{l}\text { Kane et al. } \\
1993\end{array}$ & 1986-87 & 2,507 & $\begin{array}{l}\text { Greater } \\
\text { Banjul }\end{array}$ & $14-24$ & 28 & 73 \\
\hline Guinea & $\begin{array}{l}\text { Görgen et } \\
\text { al. } 1998\end{array}$ & 1995 & 3,603 & $\begin{array}{l}3 \text { towns, } \\
37,000- \\
100,000 \\
\text { population }\end{array}$ & $15-24$ & 50 & 76 \\
\hline Kenya & $\begin{array}{l}\text { Ajayi et al. } \\
1991\end{array}$ & 1985 & 3,316 & $\begin{array}{l}\text { Nine } \\
\text { districts }\end{array}$ & $12-19$ & 39 & 62 \\
\hline Kenya & $\begin{array}{l}\text { Kiragu and } \\
\text { Zabin } \\
1993,1995\end{array}$ & 1989 & 3,032 & $\begin{array}{l}\text { Nakuru } \\
\text { District }\end{array}$ & $\begin{array}{c}\text { Not } \\
\text { specified }^{a}\end{array}$ & 26 & 65 \\
\hline Nigeria & $\begin{array}{l}\text { Amazigo } \\
\text { et al. } 1997\end{array}$ & 1993 & 1,655 & $\begin{array}{l}\text { Anambra } \\
\text { and Enugu } \\
\text { states }\end{array}$ & $14-25$ & 40 & 40 \\
\hline Tanzania & $\begin{array}{l}\text { Matasha } \\
\text { et al. } 1998\end{array}$ & $\begin{array}{c}\text { Not } \\
\text { specified }\end{array}$ & 892 & $\begin{array}{l}\text { Mwanza } \\
\text { region }\end{array}$ & $12-24$ & 63 & 84 \\
\hline Zimbabwe & $\begin{array}{l}\text { Boohene et } \\
\text { al. } 1991\end{array}$ & 1986 & 1,332 & Harare & $14-24$ & 14 & 49 \\
\hline
\end{tabular}

aPrimary, secondary, and vocational school students. 
pling design is much less salient (Gage-Brandon and Meekers 1993; Meekers 1994). For example, among 20-24-year-old women in eight anglophone African countries, the proportion reporting sexual experience before age 20 ranges from 26 percent to 60 percent (Mensch, Bruce, and Greene 1998). Is there a genuine difference, for example, between the behavior of adolescent girls in Zimbabwe and Zambia? Or, does the fact that 28 percent of girls report premarital sex in Zimbabwe and 50 percent in Zambia reflect a greater willingness to acknowledge the behavior in one country compared to the other?

The apparent acceptance by many researchers of the reported rates of sexual activity among adolescent girls is surprising given that sex before a formal union is considered inappropriate in many, if not most countries in the region. Therefore, it is reasonable to expect that substantial numbers of girls would find great difficulty in admitting to having sex outside a socially sanctioned relationship (Dare and Cleland 1994). Moreover, the embarrassment that adults — even young adults—-feel when questioned by other adults on sexual issues is likely to be compounded when older interviewers try to obtain first-hand information from adolescents about their sex lives. Eliciting this information is apt to be particularly difficult in countries such as Kenya, where the Catholic Church and evangelical Protestant churches are highly influential, where premarital abstinence is aggressively promoted, and where discovery of a pregnancy means expulsion from school.

As part of a research project investigating the impact of school quality on adolescents, a survey was conducted in 1996 in rural areas of three Kenyan districts-Kilifi, Nakuru, and Nyeri-among 774 adolescents aged 12-19. One goal of the project was to assess the impact of the quality of schools on adolescent sexual initiation. Despite efforts to encourage respondents to answer questions honestly, by conducting focus-group discussions in the study communities to get a better sense of how best to ask sensitive questions of young people, we believe there was considerable underreporting of premarital sex among adolescent girls in Nyeri, one of the three districts in the study. Figure 1 compares the reported probability of premarital sex separately by district and sex of respondent. ${ }^{2}$

In Kilifi and Nyeri districts, girls report significantly lower levels of premarital sexual activity than do boys, whereas in Nakuru the sex difference is much smaller. We 
Figure 1 Probability of adolescents aged 12-18 engaging in premarital sex, by district, Kenya, 1996 (weighted)
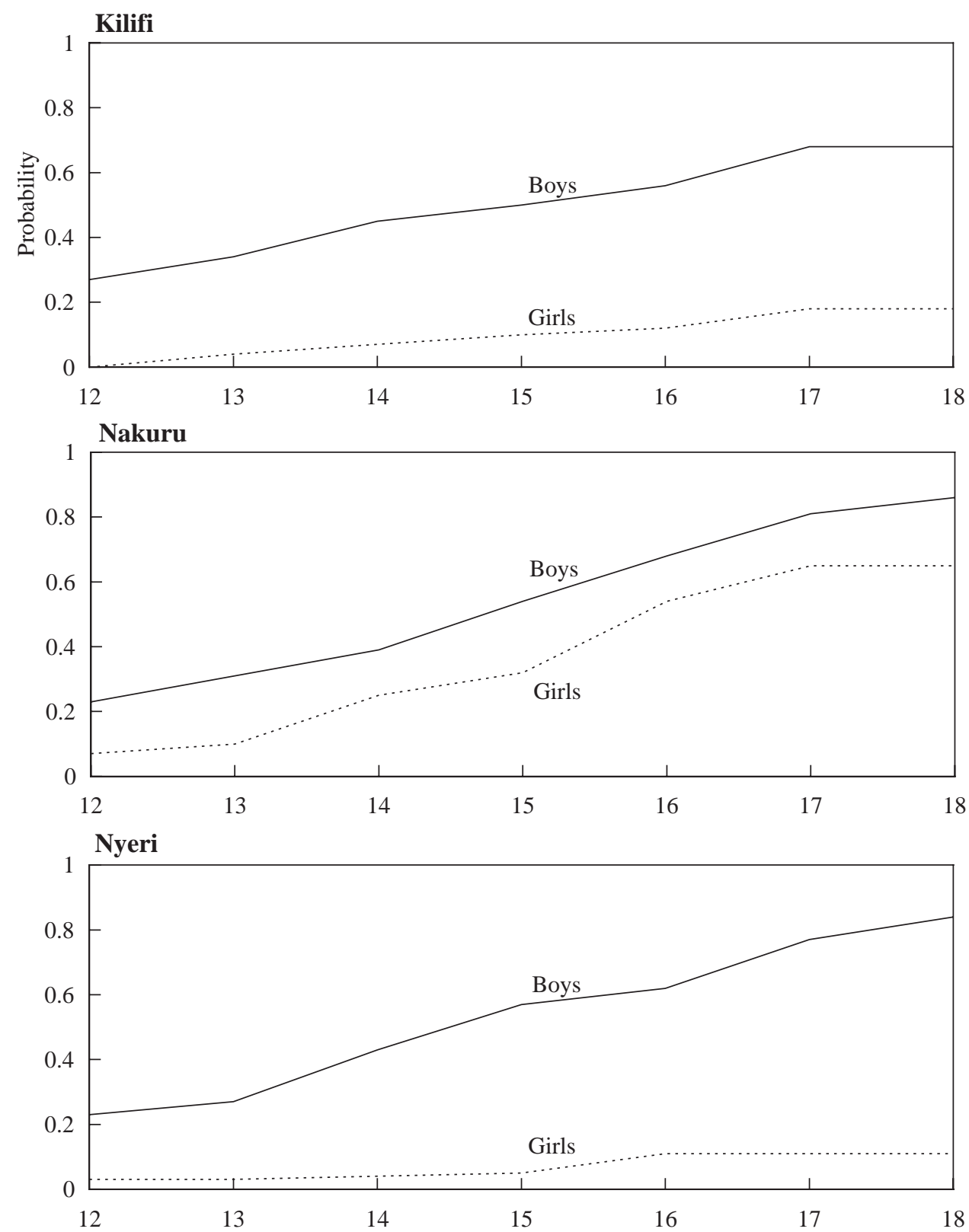
believe reports that girls in Kilifi are considerably less likely than boys to have sex to be accurate. Kilifi is located in Coast Province, which is arguably one of the poorest if not the poorest and most conservative province in the country, with the lowest level of female education and employment, and the lowest level of male approval of family planning (NCPD et al. 1999). Moreover, Kilifi has a substantial Islamic minority (about 20 percent of adolescents in the study sample). It is an area where girls still marry early, are less likely to attend school, and are monitored more closely than are girls in other areas of Kenya. On the other hand, we suspect that girls in Nyeri have higher levels of premarital sex than they report, levels comparable to those in Nakuru.

One explanation for the differences in reporting between the two districts is that Nyeri is much more homogeneous than Nakuru. Nakuru is home to a wide variety of ethnic groups, whereas Nyeri is composed largely of Kikuyus. Whereas Nakuru's ethnic diversity might allow girls more freedom to admit to being sexually experienced, Nyeri's tight-knit, comparatively closed community, with strong cultural taboos against open discussion of sexual behavior, might discourage frank reporting. Alternatively, of course, the differences between Nakuru and Nyeri may be real.

Additional evidence that reporting of sexual activity is problematic in Kenya comes from research carried out by the Population Council in conjunction with the Ministry of Health in Kisumu, a district in Nyanza Province in the western part of the country. As part of a study to identify the determinants of the spread of HIV infection, a population-based survey was conducted in Kisumu Municipality in which 1,889 men and women aged 15-49 were asked about their sexual behavior using interviewer-administered questionnaires. In addition, blood and urine samples collected from respondents were tested for HIV and a variety of other sexually transmitted infections (Chege, Rutenberg, and Kahindo 1999). Among the 43 men who claimed they were not sexually active, none was HIV positive. Among the 65 women aged 15-24 in Kisumu who claimed they were not sexually active, 17 percent were HIV positive. ${ }^{3}$ While the sample size is small, these so-called virgin infections are clear evidence of underreporting of sexual activity among young women.

Not only are the reported levels of sexual activity among females questionable, they may also be so among males. Indeed, boys may overreport sexual activity because 
such experience is often considered a badge of honor among men and a necessary rite of passage to adulthood (Erulkar and Mensch 1997).

The goal of this paper is to assess whether audio computer-assisted self-interviewing (audio-CASI), a technique designed in the United States to collect data on sensitive behaviors and adapted by Population Council staff to respondents unfamiliar with computer technology, is feasible to use in a developing-country setting and whether it produces greater reporting of sexual activity and related behaviors among girls, and possibly lower reporting among boys, than traditional survey methods, namely interviewer-administered and self-administered questionnaires.

\section{Audio Computer-Assisted Self-INTERVIEWING}

Survey researchers in the U.S. have long been concerned about the quality of data on sensitive behaviors. Computerized questionnaire administration has been designed to address concerns about both underreporting and the influence of the interviewer on survey responses. With audio computer-assisted self-interviewing, computer software is designed so that the respondent hears both the question and the response categories through headphones. The questions can also be displayed simultaneously on the computer screen, although they need not be read if the respondent prefers to listen or is unable to read. The respondent answers each question by pressing a number on a keypad or computer keyboard. The advantage of audio-CASI over face-to-face interviews is that there is much greater privacy, as neither the investigator nor anyone else in the household or area where the interview is being conducted hears the question or response. Moreover, unlike self-administered interviewing, which requires that the respondent be literate and competent to fill out a questionnaire, audio-CASI can be used without the respondent's reading the questions on the computer screen. Finally, with audio-CASI, the researcher does not have to be concerned with differences in interviewer characteristics or in interviewing styles (Tourangeau, Rips, and Rasinski 2000).

Audio-CASI has been successfully used in U.S. surveys, including the National Survey of Family Growth, the National Survey of Adolescent Males, and the National Longitudinal Study of Adolescent Health. Data have been collected on injection drug use, abortion, same-gender sex, and violent behavior — with significantly higher levels of these sensitive and illegal behaviors reported in comparison both to face-to-face interviews 
and to paper and pen self-administered questionnaires (Turner, Miller, and Rogers 1997; Turner et al. 1998; Des Jarlais et al. 1999; Fu et al. 1998; Tourangeau and Smith 1996). ${ }^{4}$

A recent commentary in the journal Science, summarizing the results of a U.S. experiment comparing audio-CASI with self-administered questionnaires, argues that audio-CASI may be especially suited to collecting data in developing countries, "where overcrowded living conditions typically prevail, where literacy is relatively low, and where some of the behaviors in question may be particularly pronounced" (Bloom 1998: 847). Yet there has been very limited use of audio-CASI in developing countries (van de Wijgert et al. 2000).

We are aware of two studies that have investigated whether the use of audioCASI results in higher reporting of sensitive behaviors in developing countries. The first study, undertaken among 664 students in a college in Thailand, compared selfadministered questionnaires and audio-CASI. While the sample was too small to detect statistically significant differences in the reporting of premarital sex, ${ }^{5}$ substantial differences were found in the expected direction with audio-CASI producing higher reporting of sexual activity, particularly for females. Moreover, respondents using audio-CASI were significantly more likely to report that the questionnaire was easier to use, which the researchers believe was related to the fact that it "engaged their interest." Finally, the use of automated skip patterns with audio-CASI reduced measurement error (Rumakom et al. 1999).

The second study, undertaken in Mexico, assessed differences in reporting of induced abortion among women aged 15-55 assigned randomly to one of four interview methods: audio-CASI using a touch screen, face-to-face interviews, self-administered interviews, and a random response technique. For the random response, the woman was asked to put her hand in a bag that contained two folded sheets of paper, one asking whether she was born in April and the other asking whether she had ever had an abortion. The interviewer did not know which sheet the woman chose. ${ }^{6}$ The methods were tested in three populations: among hospital patients in Mexico City, among illiterate women in a rural area, and in a household sample in Mexico City. For all three populations, the highest reported rate of abortion was found with the random response technique, followed by the self-administered questionnaire. Reporting among those assigned to audio-CASI and face-to-face interviews was lower (Lara et al. 2001). 


\section{STUDY DESIGN}

The project reported on here was carried out in Nyeri district in Kenya from April to October 2000. It was suspected, according to findings from the earlier survey discussed above (Mensch et al. 1999), that girls in Nyeri underreport premarital sexual activity. As we noted earlier, there are strong reasons to believe that frank reporting of sexual activity is not to be expected among adolescents in Nyeri. Hence, it is a setting where large differentials in response patterns by interviewing style were thought to be likely.

While Nyeri may be considered a desirable location to assess whether the conditions of the interview have an effect on reporting of sensitive behaviors, it may well be one of the most difficult districts in Kenya in which to carry out survey research. The region, composed largely of Kikuyus, is the center of political opposition in a country where divergent political views are not well tolerated. While the province was relatively well-off in the period when President Kenyatta ruled, Nyeri's infrastructure has deteriorated markedly in recent years.

The study was based on a quasi-experimental design in which unmarried adolescent boys and girls aged 15-21 were randomly assigned to one of three interview methods: traditional face-to-face interviews, paper and pencil self-administered interviews, and audio-CASI interviews. ${ }^{7}$ Face-to-face interviews - where interviewers directly asked respondents the questions and wrote down their answers-were chosen to provide a baseline comparison with the audio-CASI method, since we expected the greatest difference in reporting between these two methods. Paper and pencil interviews - where respondents completed a handwritten questionnaire on their own, with a minimum of instruction - were included to determine whether this mode of obtaining information was an equally valid, as well as cost-efficient mode of data collection compared with audio-CASI. And, as indicated above, audio-CASI was selected in the hope that by eliminating the need for disclosure of sensitive behaviors to an interviewer, the reporting of such behaviors would be more likely.

The questionnaire used in the study was relatively short: 58 questions were included, approximately one-third of them being sensitive questions about sexual behavior, alcohol and drug use, contraceptive use, and pregnancies and births. Most of the questions had been used in previous adolescent studies conducted by the Population Council in Kenya. Upon completion of the questionnaire, an exit interview was admin- 
istered to interviewers and respondents. Several questions relating to the interview situation were asked of the interviewer, including the number of times the respondent requested assistance or clarification and the presence of others during the interview. In addition, the interviewer asked the respondent a series of questions assessing how he or she felt during the interview-for example confused, bored, or embarrassed and whether he or she was honest. The audio-CASI technology was pilot-tested in the outskirts of Nairobi before data collection began.

Eighteen interviewers were recruited for the survey and were divided into three teams of six interviewers each. In each team, one male and one female interviewer were trained to specialize in one of the survey methods and interviewed same-sex respondents. ${ }^{8}$ Each team of six interviewers was assigned one supervisor to oversee field logistics and data quality. To facilitate community acceptance, interviewers were recruited from Nyeri, ensuring that they spoke the local language. To encourage rapport with their adolescent respondents, all interviewers were under the age of 30 and many had prior interviewing experience from earlier surveys in the district, including the recently completed DHS. Upon completion of the field work, interviewers were asked to record their observations about the data collection. At various points throughout the paper, we will quote from these reports.

Whereas previous audio-CASI studies required respondents to be trained to use a computer, this study simplified the process. The respondent used a set of audio headphones to listen to the questions and a selection of response options. Answers were then entered on an external mini-keypad. ${ }^{9}$ After each answer was entered, the computer repeated the response and the adolescent was given an opportunity to change it. This repetition of answers was done to minimize data entry errors; we were concerned that respondents would make mistakes entering their answers and we wanted them to have a chance to correct their errors. The audio headphones and mini-keypad were connected to a laptop computer that was not opened during the interview and remained in its carrying case.

\section{SAMPLE}

Using population estimates from the 1989 Kenya census, a stratified sample was drawn from a random selection of locations and sublocations within each of the seven 
divisions of Nyeri district. All divisions are of roughly equal size, except for one, Mathira, which had twice the adolescent population as the others. In each of the divisions two locations were selected at random. Using census figures for the size of sublocations (the lowest administrative unit in Kenya, roughly comparable to a "village") and the proportion of the Nyeri population aged 15-21, two sublocations per location were selected to meet a minimum sample size of 4,200 adolescents. Therefore, in each of the selected locations, two sublocations were selected at random and all unmarried adolescents aged 15-21 were sampled. ${ }^{10}$

According to conventional standards for calculating sample sizes (Cohen 1992), approximately 700 surveys were collected for each interview mode (x3) and respondent's sex (x2), for a target of 4,200 adolescent interviews. With a significance criterion of .05 and power of the significance test of .80, we are able to statistically detect a minimum of 7 percent difference in proportions reporting a specific activity across interview modes. Table 2 illustrates the outcome of the sampling assignments across the three interviewer modes by sex.

For each cell, the target sample size was 700. To achieve that number of surveys, listings of all household members were completed the day before interviewing in a location. If there was an adolescent in the household, he or she was randomly assigned to one of the three interviewing modes using prelabeled assignment forms. ${ }^{11}$ While a process of random assignment to the three modes was supposed to be followed, Table 2 illustrates that we did not achieve the expected uniform distribution across interview modes. ${ }^{12}$

It is difficult to determine the reason behind the nonrandom assignment. Anecdotal evidence suggests that the interviewers, under pressure to complete the surveys in a particular locale and facing increasing antagonism from a suspicious population, were purposely not allocating interviews to the audio-CASI method; that is, on occasion, they deliberately avoided listing households with adolescents on the assignment forms when audio-CASI was the specified interview mode. ${ }^{13}$ Another explanation, suggested by the field work supervisor, is that staff who were assigned to carry out face-to-face interviews or who were in charge of self-administered interviews over-allocated respondents to their own interview mode with the hope that, by conducting more interviews, they would be looked on favorably by Population Council staff in charge of hiring for future studies. There is some evidence from analyses of the household data that three of the 12 
Table 2 Sampling counts by interview mode and sex

\begin{tabular}{|c|c|c|c|c|c|c|c|}
\hline Boys & \multicolumn{2}{|c|}{$\begin{array}{l}\text { Interviewer- } \\
\text { administered }\end{array}$} & \multicolumn{2}{|c|}{$\begin{array}{c}\text { Self- } \\
\text { administered }\end{array}$} & \multicolumn{2}{|c|}{$\begin{array}{l}\text { Audio-CASI- } \\
\text { administered }\end{array}$} & Total \\
\hline Target sample size & 700 & $(33 \%)$ & 700 & $(33 \%)$ & 700 & $(33 \%)$ & 2100 \\
\hline Assigned surveys & 954 & $(35 \%)$ & 925 & $(34 \%)$ & 854 & $(31 \%)$ & 2733 \\
\hline Completed surveys & 829 & $(37 \%)$ & 750 & $(33 \%)$ & 694 & $(31 \%)$ & 2273 \\
\hline \multicolumn{8}{|l|}{ Girls } \\
\hline Target sample size & 700 & $(33 \%)$ & 700 & $(33 \%)$ & 700 & $(33 \%)$ & 2100 \\
\hline Assigned surveys & 847 & $(35 \%)$ & 869 & $(35 \%)$ & 740 & $(30 \%)$ & 2456 \\
\hline Completed surveys & 732 & $(35 \%)$ & 762 & $(36 \%)$ & 599 & $(29 \%)$ & 2093 \\
\hline \multicolumn{8}{|l|}{ Total } \\
\hline Target sample size & 1400 & $(33 \%)$ & 1400 & $(33 \%)$ & 1400 & $(33 \%)$ & 4200 \\
\hline Assigned surveys & 1801 & $(35 \%)$ & 1794 & $(35 \%)$ & 1594 & $(31 \%)$ & 5189 \\
\hline Completed surveys & 1561 & $(36 \%)$ & 1512 & $(35 \%)$ & 1293 & $(29 \%)$ & 4366 \\
\hline Response rate & \multicolumn{2}{|c|}{$87 \%$} & \multicolumn{2}{|c|}{$84 \%$} & \multicolumn{2}{|c|}{$81 \%$} & $84 \%$ \\
\hline
\end{tabular}

non-CASI interviewers disproportionately allocated respondents to their own interview method, but this does not represent a large enough number of interviews to account for the entire problem.

The effect of the nonrandom assignment is unclear; perhaps eligible adolescents who might have been excluded from the audio-CASI interview or included as extra respondents for the other two methods differ in their propensity to report sensitive behaviors. However, given the large sample size and the fact that the vast majority of respondents were assigned legitimately, nonrandom assignment of a small number of respondents is not likely to have a large impact on the results.

In addition to issues of assignment, audio-CASI and to a lesser extent the selfadministered mode had higher rates of nonresponse: 19 percent of the audio-CASI and 16 percent of the self-administered interviews were not completed, compared with 13 percent for interviewer-administered questionnaires. A breakdown of the reasons for noncompletion by interview mode indicates that audio-CASI had significantly higher rates of respondents not being available for interviews, suggesting deliberate avoidance. It may well be that those who refused to be interviewed, especially those who refused to be interviewed with the computer, differ from the respondents in the sample in terms of their level of comfort in answering sensitive questions. 
Table 3 shows the distribution of respondents by interview mode and by selected demographic, individual, and household characteristics. The table indicates some significant differences in respondent characteristics by mode. For example, compared with interviewer-administered respondents, audio-CASI respondents are significantly more likely to go to church and to live in households with finished floors and electricity, and self-administered respondents are more likely to have piped water. Despite differences

Table 3 Selected characteristics of respondents by interview mode

\begin{tabular}{|c|c|c|c|}
\hline & $\begin{array}{l}\text { Interviewer- } \\
\text { administered }\end{array}$ & $\begin{array}{c}\text { Self- } \\
\text { administered }\end{array}$ & $\begin{array}{l}\text { Audio-CASI- } \\
\text { administered }\end{array}$ \\
\hline \multicolumn{4}{|l|}{ Respondent characteristics } \\
\hline Respondent's age & 17.5 & 17.5 & 17.4 \\
\hline Ethnicity: Kikuyu (omitted=other) & $95 \%$ & $95 \%$ & $95 \%$ \\
\hline Catholic (omitted=Protestant) & $33 \%$ & $40 \% * * *$ & $41 \% * * *$ \\
\hline $\begin{array}{l}\text { Number of times attended church } \\
\text { in the last week }\end{array}$ & 1.0 & $1.4 * * *$ & $2.2 * * *$ \\
\hline $\begin{array}{l}\text { Respondent attended secondary school } \\
\text { (omitted=primary or less) }\end{array}$ & $33 \%$ & $33 \%$ & $36 \% *$ \\
\hline Currently enrolled & $52 \%$ & $49 \%$ & $56 \% *$ \\
\hline Currently works for cash & $28 \%$ & $33 \% * *$ & $24 \% * *$ \\
\hline \multicolumn{4}{|l|}{ Household structure } \\
\hline $\begin{array}{l}\text { Lives with both parents (omitted=lives } \\
\text { with neither parent) }\end{array}$ & $47 \%$ & $58 \% * * *$ & $53 \% * * *$ \\
\hline Lives with mother or father & $29 \%$ & $25 \% *$ & $30 \%$ \\
\hline Number of adolescent boys in household & .76 & .73 & .80 \\
\hline Number of adolescent girls in household & .66 & .67 & .69 \\
\hline $\begin{array}{l}\text { Number of people who slept in household } \\
\text { previous night }\end{array}$ & 4.8 & $4.4 * * *$ & $4.5^{* *}$ \\
\hline \multicolumn{4}{|l|}{ Household characteristics } \\
\hline $\begin{array}{l}\text { Number of items owned: livestock, cash } \\
\text { crops, or land }\end{array}$ & 2.4 & $1.9 * * *$ & $2.1 * * *$ \\
\hline $\begin{array}{l}\text { Household has piped water (omitted=river, } \\
\text { pond, stream) }\end{array}$ & $31 \%$ & $37 \% * *$ & $30 \%$ \\
\hline Household has well water & $57 \%$ & $49 \% * * *$ & $54 \%$ \\
\hline $\begin{array}{l}\text { Household has flush toilet } \\
\text { (omitted=other, none) }\end{array}$ & $4 \%$ & $8 \% * * *$ & $10 \% * * *$ \\
\hline Household has finished floors & $24 \%$ & $26 \%$ & $31 \% * * *$ \\
\hline Household has electricity & $7 \%$ & $15 \% * * *$ & $16 \% * * *$ \\
\hline Number of rooms used for sleeping & 3.2 & $3.0 * * *$ & $3.4 * * *$ \\
\hline
\end{tabular}

$* \mathrm{p}<.05 * * \mathrm{p}<.01 * * * \mathrm{p}<.001$. Significance based on comparison with interviewer mode. 
in respondent characteristics across interview modes, the absence of any systematic patterns by mode is reassuring; however, because these characteristics are potentially related to our outcome variable, we controlled for them in the subsequent analyses.

\section{EXPECTATIONS AND HYPOTHESES}

As suggested above, Nyeri district in Kenya was selected because previous research on the impact of school quality on adolescent behavior indicated large differentials in reporting of sexual activity between boys and girls on interviewer-administered surveys (Mensch et al. 1999). In that study, four times as many boys as girls aged 12-18 reported having premarital sex. While we expect higher rates of sex among boys, the difference is so large that it suggests that girls were underreporting and boys overreporting premarital sexual activity, particularly given that boys overwhelmingly report girlfriends rather than sex workers as sexual partners.

We expect that when adolescents are asked about sensitive behaviors in a private and anonymous interview setting, there is a greater likelihood of obtaining honest responses. The need for approval and the inclination to conform to social standards of behavior underlie the respondent-interviewer dynamic that leads to the censoring or changing of answers to sensitive questions. According to Tourangeau, Rips, and Rasinski (2000: 257), this tendency to alter one's responses is "situational," that is, "the respondent is concerned, at least in part, about the interviewer's approval or disapproval. The distortion, or editing... depends on the presence of an interviewer, the topic of the question and the facts about the respondent's conduct or attitudes." In this regard, audioCASI interviewing, in offering a degree of privacy to the respondent, should provide a greater sense of comfort about divulging sensitive information. This leads to the following hypotheses: (a) adolescent girls are expected to report higher levels of premarital sexual activity in the audio-CASI mode and on the self-administered questionnaire than in the interviewer method of survey administration; (b) adolescent boys are expected to report lower levels of premarital sexual activity in the audio-CASI interview and on the self-administered questionnaire than in the interviewer method of survey administration. Note that premarital sexual activity is defined according to whether or not the respondents, all of whom are unmarried, report ever having had sexual intercourse. 
Because it is more difficult to assess the degree to which respondents' perceptions of confidentiality vary according to whether they were interviewed with the computer or with a self-administered questionnaire, we did not have particular expectations regarding differences in reporting of sexual activity between these two modes. Although the degree of privacy is, in theory, the same for both, in that the interviewer does not have direct access to the respondent's answers at the time they are given, perceived confidentiality may differ when answers are written on a piece of paper compared to when they are entered into a computer via an external mini-keypad.

In addition to questions about sexual activity, there were several questions about the respondent's use of alcohol and marijuana. Given the environment in Kenya, use of alcohol and marijuana is likely to be underreported in interviewer-administered surveys by both girls and boys. While we expect to find higher levels of reporting in the selfadministered and audio-CASI interviews than in the interviewer-administered mode, substantively interesting differences across interview modes will be harder to observe among girls since substance use is limited to a very small percentage of respondents. ${ }^{14}$

\section{METHODS AND RESULTS}

Because the dependent variables of interest are dichotomous, we used logistic regression analysis to obtain estimates and predicted values for reporting of each of the behaviors by interview mode. ${ }^{15}$ Although t-tests for independent samples would also have served as a tool for measuring the significance of differences obtained across interview modes, logistic regression was selected so that secondary variables could be included to control for the fact that the random assignment of households to each interview mode was apparently not completely adhered to.

Table 4 provides basic descriptive frequencies for each of the dependent variables of interest by interview mode. Significant differences are found across interview methods, sometimes as much as a 20 percent higher or lower level of reporting depending on the mode of interview. However, the pattern of differences is not systematic, nor is it consistent with our expectations. Before discussing the substantive implications of these findings, we consider the results of the multivariate estimation.

The results of the logistic estimation for the reporting of premarital sexual activity are shown in Table 5. Two models were estimated. The first is a baseline model 
Table 4 Percent reporting sensitive behaviors by interview mode and sex

\begin{tabular}{|c|c|c|c|c|c|c|}
\hline & \multicolumn{3}{|c|}{ Girls 15-21 } & \multicolumn{3}{|c|}{ Boys 15-21 } \\
\hline & $\begin{array}{c}\% \\
\text { Interviewer- } \\
\text { administered }\end{array}$ & $\begin{array}{c}\% \\
\text { Self- } \\
\text { administered }\end{array}$ & $\begin{array}{c}\% \\
\text { Audio-CASI- } \\
\text { administered }\end{array}$ & $\begin{array}{c}\% \\
\text { Interviewer- } \\
\text { administered }\end{array}$ & $\begin{array}{c}\% \\
\text { Self- } \\
\text { administered }\end{array}$ & $\begin{array}{c}\% \\
\text { Audio-CASI- } \\
\text { administered }\end{array}$ \\
\hline \multicolumn{7}{|l|}{ Sexual activity } \\
\hline $\begin{array}{l}\text { Ever had a girlfriend } \\
\text { or boyfriend }\end{array}$ & 57 & 46 & 40 & 70 & 59 & 54 \\
\hline $\begin{array}{l}\text { Ever had sexual } \\
\text { intercourse }\end{array}$ & 46 & 28 & 23 & 67 & 45 & 39 \\
\hline \multicolumn{7}{|l|}{ HIV and STIs } \\
\hline Ever had an STI & 2 & 7 & 4 & 5 & 8 & 5 \\
\hline $\begin{array}{l}\text { Would tell partner } \\
\text { if had an STI }\end{array}$ & 82 & 80 & 91 & 73 & 76 & 83 \\
\hline $\begin{array}{l}\text { Know someone with } \\
\text { or who has died of } \\
\text { HIV/AIDS }\end{array}$ & 66 & 56 & 50 & 65 & 52 & 53 \\
\hline $\begin{array}{l}\text { Perceived themselves } \\
\text { as having great risk of } \\
\text { HIV/AIDS }\end{array}$ & 16 & 23 & 48 & 16 & 17 & 53 \\
\hline Has had an HIV test & 15 & 14 & 22 & 7 & 14 & 20 \\
\hline $\begin{array}{l}\text { Would tell partner } \\
\text { if had HIV/AIDS }\end{array}$ & 80 & 80 & 90 & 66 & 72 & 84 \\
\hline \multicolumn{7}{|l|}{ Drug and alcohol use } \\
\hline Ever used alcohol & 12 & 6 & 6 & 54 & 31 & 35 \\
\hline Ever used marijuana & 1 & 1 & 1 & 9 & 6 & 6 \\
\hline
\end{tabular}

where the dependent variable is regressed only on the interview method and sex. Since we expected differential effects of the interview method by sex for most of the questions-for example, in the case of sexual activity, boys were expected to overreport and girls to underreport in the interviewer-administered mode-interaction variables that captured the interviewer mode by sex were included in the regressions. ${ }^{16}$ The second, "full" model is the baseline model with added control variables. The reported coefficients are relative risk ratios, with the interview mode serving as a baseline of comparison. Since the estimated coefficients are not easily interpreted, the bottom panel of Table 5 shows the predicted percentages from the logistic regression of boys and girls reporting ever having sex by interview mode. The predicted percentages in the baseline model give the actual percentages of boys and girls reporting premarital sex by interview mode as reported in Table 4. 
Table 5 Odds ratios from logistic regression of ever having had sexual intercourse (standard errors in parentheses)

\begin{tabular}{|c|c|c|}
\hline & Baseline model & Full model \\
\hline \multicolumn{3}{|l|}{ Interview setting } \\
\hline Interviewer mode & 1.00 & 1.00 \\
\hline Self-administered mode & $.44(.06)^{* *}$ & $.42(.08)^{* * *}$ \\
\hline Audio-CASI mode & $.34(.04)^{* *}$ & $.39(.06)^{* * *}$ \\
\hline Sex: Male (omitted=female) & $2.32(.31)^{* *}$ & $1.95(.35)^{* * *}$ \\
\hline Sex $x$ self-administered mode & $.94 \quad(.14)$ & $.91(.18)$ \\
\hline Sex $\mathrm{x}$ audio-CASI mode & $.95 \quad(.18)$ & $.82(.18)$ \\
\hline \multicolumn{3}{|l|}{ Respondent characteristics } \\
\hline Respondent's age & & $1.40(.04)^{* * *}$ \\
\hline Ethnicity: Kikuyu (omitted=other) & & $.94(.21)$ \\
\hline Catholic (omitted=Protestant) & & $1.08(.08)$ \\
\hline Number of times attended church in the last week & & $.88(.03)^{* * *}$ \\
\hline Respondent attended secondary school (omitted=primary or & less) & $.87(.86)$ \\
\hline Currently enrolled & & $.48(.04)^{* * *}$ \\
\hline Currently works for cash & & $1.46(.09)^{* * *}$ \\
\hline \multicolumn{3}{|l|}{ Household structure } \\
\hline Lives with both parents (omitted=lives with neither parent) & & $1.06(.12)$ \\
\hline Lives with mother or father & & $.77(.07)^{* *}$ \\
\hline Number of adolescent boys in household & & $.94(.07)$ \\
\hline Number of adolescent girls in household & & $.83(.06)^{*}$ \\
\hline Number of people who slept in household previous night & & $1.02(.01)$ \\
\hline \multicolumn{3}{|l|}{ Household characteristics } \\
\hline Number of items owned: livestock, cash crops, or land & & $1.13(.07)^{*}$ \\
\hline Household has piped water (omitted=river, pond, stream) & & $.90(.09)$ \\
\hline Household has well water & & $1.06(.14)$ \\
\hline Household has flush toilet (omitted=other, none) & & $.90(.10)$ \\
\hline Household has finished floors & & $1.06(.08)$ \\
\hline Household has electricity & & $.87(.12)$ \\
\hline Number of rooms used for sleeping & & $.97(.02)$ \\
\hline $\mathbf{N}$ & 4235 & 4177 \\
\hline \multicolumn{3}{|l|}{ Predicted percentages by mode } \\
\hline \multicolumn{3}{|l|}{ Boys } \\
\hline Interviewer mode & 67 & 61 \\
\hline Self-administered mode & 45 & 42 \\
\hline Audio-CASI mode & 39 & 38 \\
\hline \multicolumn{3}{|l|}{ Girls } \\
\hline Interviewer mode & 46 & 48 \\
\hline Self-administered mode & 28 & 31 \\
\hline Audio-CASI mode & 23 & 30 \\
\hline
\end{tabular}

$* \mathrm{p}<.05 * * \mathrm{p}<.01 * * * \mathrm{p}<.001$ 
As can be discerned from the predicted values and related coefficients in Table 5, there is a substantial and significant difference in reported rates of premarital sex across interview modes. For both sexes there is a lower reporting with audio-CASI. For boys, this effect is in the expected direction with a 23 percent drop in reported sexual activity in the audio-CASI mode. This large differential provides strong evidence that the nature of the interview context has an effect on response patterns to sensitive questions. Further, it appears to confirm the notion that boys are overreporting their sexual activity in the interviewer mode. More troubling, however, is the parallel pattern of results obtained for girls. Although there is clearly a large differential effect by interview mode, the effect is not in the expected direction, with girls reporting twice as much sexual activity in the interviewer mode than with audio-CASI. In other words, it appears that girls are more inhibited about reporting premarital sex in the self-administered and audio-CASI interviews than in an interviewer-administered survey. ${ }^{17}$

As we indicated earlier, at the end of the interview the interviewer answered several questions about the interview context, and the respondent was also asked questions to elicit his or her reactions to the interview. We collected these data in the hope that they would help shed light on the findings. Table 6 indicates how the respondent's reaction to the interview and other interview characteristics vary by interview mode. What is most encouraging is that the audio-CASI respondents did not have difficulty with the technology, at least as measured by the number of times they asked for help. On the other hand, examining respondent reactions to the interview, girls assigned to audio-

Table 6 Interview characteristics of respondent by interview mode

\begin{tabular}{|c|c|c|c|c|c|c|}
\hline \multirow{2}{*}{$\begin{array}{l}\text { Interview } \\
\text { characteristics }\end{array}$} & \multicolumn{2}{|c|}{$\begin{array}{l}\text { Interviewer- } \\
\text { administered }\end{array}$} & \multicolumn{2}{|c|}{$\begin{array}{c}\text { Self- } \\
\text { administered }\end{array}$} & \multicolumn{2}{|c|}{$\begin{array}{l}\text { Audio-CASI- } \\
\text { administered }\end{array}$} \\
\hline & Boys & Girls & Boys & Girls & Boys & Girls \\
\hline No. of times requested help/clarification & 1.5 & 1.5 & 2.1 & 1.8 & 1.5 & 1.6 \\
\hline Other people present during interview & $1 \%$ & $1 \%$ & $1 \%$ & $1 \%$ & $21 \%$ & $31 \%$ \\
\hline Confused & $1 \%$ & $1 \%$ & $5 \%$ & $14 \%$ & $15 \%$ & $11 \%$ \\
\hline Embarrassed & $1 \%$ & $13 \%$ & $6 \%$ & $14 \%$ & $3 \%$ & $11 \%$ \\
\hline Uncomfortable & $8 \%$ & $5 \%$ & $5 \%$ & $10 \%$ & $5 \%$ & $6 \%$ \\
\hline Bored & $2 \%$ & $1 \%$ & $8 \%$ & $4 \%$ & $6 \%$ & $6 \%$ \\
\hline Not "very honest" & $35 \%$ & $13 \%$ & $43 \%$ & $28 \%$ & $15 \%$ & $26 \%$ \\
\hline
\end{tabular}


CASI along with those who were given the self-administered version were more likely to be confused and less likely to be "very honest." ${ }^{18}$ In contrast, boys assigned to audioCASI were more likely to report being very honest. Yet, when we analyzed reporting of sex by method of interview and the respondent's assessment of how honest he or she was, the results were not at all illuminating. Among audio-CASI girls, 22 percent of those who said they were not very honest reported they had sex compared to 23 percent of those who said they were very honest. And, for audio-CASI boys, the more honest they said they were, the greater the reporting of sex: 42 percent vs. 24 percent.

What is perhaps most striking about Table 6 is that despite the best efforts of our interviewers to maintain privacy, fully one-quarter of audio-CASI surveys took place with others present, whereas for interviewer- and self-administered modes this proportion was around 1 percent. The presence of others was undoubtedly due to the novelty and spectacle of the computer and related equipment, as well as to the suspicions of parents and other community members about the computerized method of interviewing. Surprisingly, the presence of others did not affect the respondent's willingness to report sensitive behavior in the audio-CASI interviews. It appears that the respondents realized that bystanders could not hear the questions and therefore would have no inkling of their responses. Among boys interviewed with audio-CASI, 41 percent of those with others present reported having had sex compared to 39 percent of boys with no one present. And for girls, 27 percent of those with others present reported having sex compared to 21 percent with no one present. In short, the presence of others during the audio-CASI interview did not seem to affect reporting.

As discussed above, in addition to comparing the level of premarital sex by type of interview, we also compared the reporting of other sensitive behaviors across interview mode. Table 7 shows the predicted percentages for other outcome variables of interest that are not conditional on reporting of sex. ${ }^{19}$ Focusing on the response to the question of whether the respondent has ever had a boyfriend or girlfriend, the pattern is similar to the response to the question about sexual intercourse; the interviewer-administered mode elicits higher reporting than either the audio-CASI or self-administered methods. For alcohol use, the interviewer-administered method again produces a higher response, although responses in the audio-CASI method are higher than in the selfadministered method. For drug use and STIs, the differences across modes are minimal. 
Table 7 Predicted percentages from logistic regressions

\begin{tabular}{|c|c|c|c|c|c|c|}
\hline & \multicolumn{3}{|c|}{ Girls 15-21 } & \multicolumn{3}{|c|}{ Boys 15-21 } \\
\hline & $\begin{array}{c}\% \\
\text { Interviewer- } \\
\text { administered }\end{array}$ & $\begin{array}{c}\% \\
\text { Self- } \\
\text { administered }\end{array}$ & $\begin{array}{c}\% \\
\text { Audio-CASI- } \\
\text { administered }\end{array}$ & $\begin{array}{c}\% \\
\text { Interviewer- } \\
\text { administered }\end{array}$ & $\begin{array}{c}\% \\
\text { Self- } \\
\text { administered }\end{array}$ & $\begin{array}{c}\% \\
\text { Audio-CASI- } \\
\text { administered }\end{array}$ \\
\hline \multicolumn{7}{|l|}{ Sexual activity } \\
\hline $\begin{array}{l}\text { Ever had a girlfriend or } \\
\text { boyfriend }\end{array}$ & 59 & 48 & 45 & 67 & 57 & 54 \\
\hline Ever had sexual intercourse & 48 & 31 & 30 & 61 & 42 & 38 \\
\hline \multicolumn{7}{|l|}{ HIV and STIs } \\
\hline Ever had an STI & 3 & 7 & 5 & 5 & 7 & 4 \\
\hline $\begin{array}{l}\text { Would tell partner if had } \\
\text { an STI }\end{array}$ & 85 & 82 & 92 & 69 & 73 & 79 \\
\hline $\begin{array}{l}\text { Know someone with or who } \\
\text { has died of HIV/AIDS }\end{array}$ & ho & 59 & 51 & 64 & 53 & 54 \\
\hline $\begin{array}{l}\text { Perceived themselves as } \\
\text { having great risk of } \\
\text { HIV/AIDS }\end{array}$ & 17 & 23 & 48 & 17 & 17 & 52 \\
\hline Has had an HIV test & 15 & 14 & 22 & 7 & 14 & 20 \\
\hline $\begin{array}{l}\text { Would tell partner if had } \\
\text { HIV/AIDS }\end{array}$ & 82 & 81 & 91 & 65 & 72 & 83 \\
\hline \multicolumn{7}{|l|}{ Drug and alcohol use } \\
\hline Ever used alcohol & 12 & 6 & 6 & 54 & 31 & 35 \\
\hline Ever used marijuana & 1 & 1 & 1 & 9 & 6 & 6 \\
\hline
\end{tabular}

And, for questions about HIV/AIDS, reporting is higher for audio-CASI for both males and females, especially for the question on perception of risk of HIV/AIDS. In short, there is no consistent pattern of reporting of sensitive behaviors across the three interview modes, certainly none that suggests strong confirmation of our original hypotheses. Not only does the interviewer-administered questionnaire produce unexpectedly higher rates of reporting for girls than audio-CASI for many of the behaviors, it often produces higher rates than the self-administered mode.

\section{COMMUNITY REACTION}

Before the initiation of data collection in a particular community, the supervisors met with local leaders, chiefs, educators, and clergy to gain the acceptance of the residents. However, the political climate is sufficiently volatile in Nyeri that outsiders often 
encounter hostility, and unusual events sometimes provoke distrust. As the study progressed, increased time was devoted to what was called "community publicity," including repeated discussions with community leaders. Despite these efforts, residents expressed concerns and some even displayed hostility toward the data collection teams. ${ }^{20}$ This suspicion manifested itself through frequent references by residents to devil-worshiping and child abduction - two issues of particular concern to Nyeri residents. Noted one interviewer:

In the recent past, the media has actively reported about devil worshipers and connected it with child abductions where some children have been found dead or their bodies mutilated. Since we list household members and interview young respondents...they allege that we come for the listed people.

Another interviewer wrote:

Right from day one, the issue of Satanism and association with the occult has been a major drawback to the survey. No matter how informed the public is on the survey, this issue always arises.

The anxiety and hostility were often rooted in the deteriorating economic situation in Kenya generally and in Nyeri specifically. Reported one of our interviewers:

This was a period of drought and the people were informing us that for the last three years they have gone without rainfall. As the saying goes, a hungry man is an angry man, and insecurity breeds violence. Thus it was expected that in some areas we would not get cooperation. This was manifested clearly at the...sublocation where the villagers could not understand the benefits of the interview while their children had gone for days without food, and they did not know what the future held for them.

Other interviewers noted that the deep-seated concern about premarital sex also affected the community's response to the study:

Some church leaders have also been making our work difficult by announcing to the members of their churches that people should not cooperate with us. They 
claim that we are introducing very young and innocent youths to matters pertaining to sex by asking them questions about reproductive health.

The animosity was particularly directed toward the audio-CASI interviews, since most rural Kenyans are unfamiliar with computers. Complained one interviewer:

The computer has raised a lot of concern in the community and they perceive it with a lot of suspicion in almost every sublocation.

\section{Another wrote:}

Some surprisingly have never even heard about it [the computer]. It is associated with things like devil worship.... Parents and other respondents who are interviewed using other methods go so far as claiming that computers suck human blood so the respondents fear these electronic gadgets.

Although we tried not to draw attention to the computers, word spread quickly through the community that they were being used to collect information about adolescents. Thus in many areas misinformation about the technology developed even before completion of the targeted interviews. Noting the contrast between the sophisticated technology and the hardships experienced by residents, one interviewer wrote:

In regions where the people had been hard hit by the drought, they found it mockery to have people going around asking questions with very expensive machines. To them the government seemed to have turned its back on them. They said it should sell all the computers and buy them food instead.

The fact that some residents of the district thought that the computer was having a "conversation" with respondents despite our insistence that the voice was taped may have exacerbated the situation:

The rural folks have never seen a computer, and a talking computer for that matter. Others say the computer sucks the blood while others will say that the respondent is communicating with someone overseas, underworld, underwater, or the Queen of Sheba [head of demons]. 
The playback of the respondent's answers used in the audio-CASI design may have compounded the problem:

The confirmation part after a respondent has responded to a question has been of particular concern to many because they fail to understand how the options they give as their answers [are repeated], yet we claim that voice has been taped.

Some thought the questions were being asked live by somebody in Nairobi or Mombasa, hence they were worried about their privacy.

Because of a concern that the playback of answers may have contributed to the reduced reporting of sensitive behaviors among those assigned to the audio-CASI mode, after the initial data analysis was completed we conducted a small experiment among an additional 300 adolescent girls in locations in Nyeri district that were not included in the original sample. Half of the sample was assigned to audio-CASI with playback of answers and half to audio-CASI without playback. To eliminate the possibility that respondents would question why some of their peers had their answers played back to them and others did not, all respondents within a particular location were assigned to the same group. "Playback" locations and "No playback" locations were not contiguous. At the conclusion of the computer interview, both groups were given a face-to-face exit interview that included several questions about perception of confidentiality and privacy, which had not been asked in the earlier round of data collection.

As Table 8 indicates, the results of this experiment are inconclusive. While reporting of alcohol and marijuana use and sexually transmitted infections is higher with-

Table 8 Percent of girls reporting sensitive behaviors according to whether or not answers were played back

\begin{tabular}{lcc}
\hline Behavior & Playback & No playback \\
\hline Ever had boyfriend & 48 & 36 \\
Ever had sexual intercourse & 21 & 24 \\
Ever had an STI & 6 & 13 \\
Ever used alcohol & 5 & 11 \\
Ever used marijuana & 1 & 14 \\
Know someone with AIDS & 81 & 57 \\
(N) & $(150)$ & $(150)$ \\
\hline
\end{tabular}


Table 9 Exit interview responses of girls according to whether or not answers were played back

\begin{tabular}{lcc}
\hline & Playback $(\boldsymbol{\%})$ & No playback $(\boldsymbol{\%})$ \\
\hline Interview confidential & 90 & 91 \\
Interview private & 88 & 94 \\
Community will find out answers & 3 & 6 \\
Think someone was listening & 4 & 6 \\
(N) & $(150)$ & $(150)$ \\
\hline
\end{tabular}

out the playback, reporting that one has a boyfriend and that one knows someone with AIDS is lower and there is only a marginal difference between playback and no playback in the reporting of sex. Moreover, as shown in Table 9, which reports on the results of the exit interview, respondents without playback did not feel the interview was more confidential nor were they less likely to believe that someone was listening to them. Despite claims by the field staff that our results were compromised by the playing back of responses, this small experiment suggests that the reduced levels of reporting of sensitive behaviors in the audio-CASI arm of the main survey cannot be explained by this repetition. In short, it appears that adolescent respondents in Nyeri are simply anxious about using the computer to answer questions about these behaviors.

\section{CONCLUSION}

This project is one of the first attempts to assess and improve the quality of survey data on adolescent sexual behavior in sub-Saharan Africa. Analysis of data collected from nearly 4,400 unmarried adolescents aged 15-21 in Nyeri indicates that the interview context has a substantial effect on responses to sensitive questions about sexual and other risky behaviors among young people. Indeed, there are large and significant differences in reported rates of premarital sex across the three interview modes: face-toface interviewing, paper and pencil self-administered interviews, and audio-CASI. In particular, the finding of lower reported levels of premarital sex among girls with audioCASI is unexpected and perplexing, and undermines our ability to predict the nature and magnitude of the response bias in interviewer-administered surveys. Clearly, researchers who rely on survey data need to be more critical of the information collected from young people in developing countries and, at the very least, should put wide confidence intervals around estimates of the prevalence of particular behaviors. 
Audio-CASI is now considered to be the method of choice for data collection on sensitive behaviors in the United States; however, as this methodological study suggests, its usefulness and applicability in Africa appear to be less certain. While there were few technical problems and while respondents were able to complete the interview with limited training, the use of computers to collect survey data has its drawbacks, and in certain settings, such as Nyeri, can have a dramatic effect on the population's reaction to the survey as well as to its implementation. The problems experienced by our interviewing team-and illustrated by their descriptions of the difficulties encountered during the field work-indicate that the use of computers heightened the anxiety, suspicion, and hostility of the population. Further, it is reasonable to suspect that the negative reaction to the computers had a direct effect on the response patterns of adolescents.

Our experience with audio-CASI leaves us with more questions than answers. Assuming our hypothesis regarding boys is correct, namely that they exaggerate their level of sexual activity in face-to-face interviews and are more likely to be honest with computer-assisted interviewing, our results can be said to confirm our prior theory. However, our assumption that girls underreport sexual activity in face-to-face interviews and are more likely to reveal their true level of sexual activity when guaranteed the privacy that the computer ostensibly affords is not confirmed by the data. It is hard to make a case that the experiment "worked" for boys and did not work for girls. Is it possible that the parents of girls and thus the girls themselves felt more threatened by the computer, and that the audio-CASI results of sexual activity among girls are underreports, while the interviewer-administered results are closer to the truth? Yet how then do we reconcile the self-administered results with the interviewer-administered results? Why should reported sexual activity among girls using the self-administered questionnaire be so much lower?

We feel that it is premature to draw firm conclusions about the efficacy of this methodology on the basis of this single experience from Nyeri. It may well be that audio-CASI did not "work" for girls simply because of the particular circumstances that exist in this district. Clearly, research is needed in additional settings before we can reach a definitive conclusion about the utility of computer interviewing for the reporting of sensitive behaviors among adolescents in sub-Saharan Africa. 
The authors gratefully acknowledge the role of their collaborators in the field research: Lucy Ng' ang'a and Maina Kimondo at the Population Council, Kenya, as well as the 18 interviewers and two supervisors who carried out the field research. They also acknowledge the technical assistance provided by Stanley Mierzwa and the administrative work of Hilary Brougher at the Population Council, New York.

Funding for this research was provided by the National Institute of Child Health and Human Development (Grant RO1 HD35700-02), the United States Agency for International Development through a cooperative agreement with the Population Council, and the Bill and Melinda Gates Foundation.

1 While researchers who have conducted adolescent surveys in sub-Saharan Africa have not focused their attention on this issue, social scientists are beginning to explore the validity and reliability of survey data among adolescents elsewhere in the developing world. A recent study of self-reports of sexual activity among adolescents in Jamaica, based on data from a three-round longitudinal survey, found that over one-third of respondents reported their sexual experience inconsistently (Eggleston et al. 2000). See also the study in Thailand discussed later (Rumakom et al. 1999). Although they do not focus solely on adolescents, DHS staff, who are concerned with the quality of data collected, recognize that underreporting of premarital sex among women is likely (see Blanc and Way 1998).

2 These figures and discussion are taken from Mensch et al. 1999.

3 These unpublished tabulations were provided by Naomi Rutenberg, a principal investigator for the project.

4 One study of self-reported drug use and sexual behavior in the U.S., which compared the reliability of audio-CASI and face-to-face interviews at two points in time using a cross-over design (where one-quarter of the sample was assigned to audio-CASI at both times, one-quarter was assigned to face-to-face at both times, 
and the other half was assigned to different modes at each time) and which assessed validity using urinalysis, did not find higher reporting of risky behaviors using the computer. The researchers attribute this to the fact that respondents, while recruited from community settings, were selected on the basis of self-reported drug use to be participants in an HIV risk-reduction study. Therefore, they were entirely comfortable reporting risky behaviors to interviewers (Williams et al. 2000). Another study, which compared reports of HIV risk behaviors using CASI (without audio) to pen and paper self-completion interviews in a national probability sample in Britain, also did not find higher rates of risky behaviors reported with the computer. The researchers suggest that the more tolerant attitudes toward homosexuality in Britain compared to the U.S. and the fact that the studies in the U.S. are conducted with disadvantaged populations may explain the absence of a difference (Johnson et al. 2001).

5 Because the researchers were testing two versions of audio-CASI, one designed in Thailand that included photos on each screen and another commercially available program, the sample was divided into three arms; this made it more difficult to detect significance.

6 To calculate the rate of abortion, the researchers doubled the percentage of women answering "yes" since there is an equal chance of choosing each question and subtracted the percentage estimated to be born in April assuming an equal likelihood of being born in each of 12 months.

7 The age range was selected because reported levels of sexual activity are low in Kenya among young people under age 15 while marriage is common after age 21 .

8 While several studies in the U.S. have found that both men and women are more likely to disclose information about sexual activity to female interviewers, a recent study found that same-sex interviewers increased the level of reporting (Catania 1997). Note that our study design does not address interviewer effects but rather focuses only on mode-of-administration effects.

9 With a purely audio design (as opposed to the more common design where audio is combined with a visual component—-that is, the respondent can also read the 
computer screen), the number of response options is limited because of potential difficulties remembering the categories that have been heard. In our survey, questions varied in the number of response categories. Many questions were dichotomous, i.e. $1=y e s, 2=$ no. Others had several options, up to a maximum of 6 , which we found posed no significant problem for the respondent.

10 One selected sublocation was replaced after being sampled, as it had been serving as a survey cluster for the Central Bureau of Statistics (CBS) for more than a decade. CBS felt that respondents in this sublocation were fatigued, having participated in two Demographic and Health Surveys and in virtually all other surveys that are fielded in the district.

11 Only one adolescent per household was assigned to the study. If there was more than one adolescent in the age range, one was selected randomly, based on a "Kish" grid. The prelabeled assignment forms allowed the interviewers to know which interview method would be used before the household interview was completed.

12 The deviation from uniformity, i.e., randomness, is significant below the .001 level.

13 Audio-CASI required the longest training and interviewing time. While training times were not documented, we recorded interview times; on average the interviewer-administered mode took 17 minutes, the self-administered 34 minutes, and audio-CASI 40 minutes.

14 However, for a fixed power of the test, at lower frequencies the sample size required to detect significant differences across modes drops substantially; thus detection of significant differences is easier (Cohen 1992).

15 The logistic regression included robust estimates of the standard errors that adjusted for potential homogeneity within the primary sampling unit resulting from the cluster design of the sample.

16 Although this difference between boys and girls is hypothesized only for the question on ever having had sexual intercourse, the interaction terms were included in all analyses, since they can detect any unexpected differences that might emerge between boys and girls. 
17 In addition to running logistic regression models with the dependent variable "ever had sexual intercourse," we also ran hazard models because there are some adolescents in our sample whose experience is censored. The results for these models parallel those for the logistic models.

18 This question had three response options, very honest (given by $73 \%$ of respondents), mostly honest (26\%), and not very honest (1\%). Because we think that respondents exaggerated their level of honesty, we created a variable with two categories: very honest and less than very honest.

19 Analyses of such "conditional" outcomes as coerced sex, pregnancy, and abortion are problematic because the sub-sample of those who answered these questions is selective. For example, respondents who report that they have not had sex when in fact they have are not asked the questions that are contingent on having had sex. Assuming, for example, that girls in the interviewer-administered mode who report being sexually active are more likely to be honest regarding other sensitive questions than the true population of girls who have had sex, we would expect smaller differences between the audio-CASI mode and the interviewer-administered mode for these sets of questions. For boys, the effect is more difficult to predict. If a subset of boys who boast about having had sex when they have not are then asked about risky and coerced sexual behavior, it is unlikely that they would admit to such behaviors. The overreporting of sex will increase the denominator for these questions in the interview-administered mode, deflating the percentage of those who report the subsequent behaviors. The net effect would be to increase the differences between the self-administered and audio-CASI modes.

20 One interviewer, in fact, was physically assaulted by some community residents. A van carrying interviewers was also stoned in another community. 


\section{References}

Ajayi, Ayo A., Leah Marangu, Janice Miller, and John M. Paxman. 1991. “Adolescent sexuality and fertility in Kenya: A survey of knowledge, perceptions, and practices," Studies in Family Planning 22(4): 205-216.

Amazigo, Uche, Nancy Silva, Joan Kaufman, and Daniel S. Obikeze. 1997. "Sexual activity and contraceptive knowledge and use among in-school adolescents in Nigeria," International Family Planning Perspectives 23(1): 28-33.

Blanc, Ann K. and Ann A. Way. 1998. "Sexual behavior, contraceptive knowledge and use among adolescents in developing countries," Studies in Family Planning 29(2): $106-116$.

Bloom, David E. 1998. "Technology, experimentation, and the quality of survey data," Science 280(5365): 847-848.

Boohene, Esther, June Tsodzai, Karen Hardee-Cleaveland, Sharon Weir, and Barbara Janowitz. 1991. "Fertility and contraceptive use among young adults in Harare, Zimbawe," Studies in Family Planning 22(4): 264-271.

Catania, Joseph A. 1997. "A model for investigating respondent-interviewer relationships in sexual surveys," in John Bancroft (ed.), Researching Sexual Behavior: Methodological Issues. Bloomington: Indiana University Press, pp. 417-435.

Chege, Jane, Naomi Rutenberg, and Maina Kahindo. 1999. Draft. "Multicentre study on factors determining the differential spread of HIV infection in African towns: Kisumu-Kenya site report." Nairobi: Population Council and Ministry of Health.

Cohen, Jacob. 1992. “A power primer,” Psychological Bulletin 112(1): 155-159.

Dare, O. O. and J. G. Cleland. 1994. "Reliability and validity of survey data on sexual behaviour," Health Transition Review: AIDS Impact and Prevention in the Developing World: Demographic and Social Science Perspectives 4 (Supplement): 93-110.

Des Jarlais, Don C., et al. 1999. “Audio-computer interviewing to measure risk behaviour for HIV among injecting drug users: A quasi-randomised trial," The Lancet 353(9165): 1657-1661. 
Eggleston, Elizabeth, Joan Leitch, and Jean Jackson. 2000. "Consistency of self-reports of sexual activity among young adolescents in Jamaica," International Family Planning Perspectives 26(2): 79-83.

Erulkar, Annabel S. and Barbara S. Mensch. 1997. "Gender differences in the dating experiences and sexual behavior of adolescents in Kenya," paper presented at the 23rd Population Conference of the International Union for the Scientific Study of Population, 11-17 October, Beijing.

Fenton, Kevin A., Anne M. Johnson, Sally McManus, and Bob Erens. 2001. "Measuring sexual behaviour: Methodological challenges in survey research," Sexually Transmitted Infections 77: 84-92.

Fu, Haishan, Jacqueline E. Darroch, Stanley K. Henshaw, and Elizabeth Kolb. 1998. "Measuring the extent of abortion underreporting in the 1995 National Survey of Family Growth," Family Planning Perspectives 30(3): 128-133, 138.

Gage-Brandon, Anastasia J. and Dominique Meekers. 1993. "Sex, contraception and childbearing before marriage in sub-Saharan Africa," International Family Planning Perspectives 19(1): 14-18, 33.

Görgen, Regina, Mohamed L. Yansané, Michael Marx, and Dominique Millimounou. 1998. "Sexual behavior and attitudes among unmarried urban youths in Guinea," International Family Planning Perspectives 24(2): 65-71.

Johnson, Anne M., et al. 2001. "Effect of computer-assisted self-interviews on reporting of sexual HIV risk behaviours in a general population sample: A methodological experiment," AIDS 2001 15: 111-115.

Jones, Elise F. and Jacqueline Darroch Forrest. 1992. "Underreporting of abortion in surveys of U.S. women: 1976 to 1988,” Demography 29(1): 113-126.

Kane, Thomas T., Rose De Buysscher, Tunde Taylor-Thomas, Tamara Smith, and Momodou Jeng. 1993. "Sexual activity, family life education, and contraceptive practice among young adults in Banjul, The Gambia," Studies in Family Planning 24(1): 50-61.

Kiragu, Karungari and Laurie S. Zabin. 1993. "The correlates of premarital sexual activity among school-age adolescents in Kenya," International Family Planning Perspectives 19(3): 92-97, 109. 
—_ 1995. "Contraceptive use among high school students in Kenya," International Family Planning Perspectives 21(3): 108-113.

Lara, Diana, Charlotte Ellertson, Claudia Diaz, and Jennifer Strickler. 2001. "Measuring the prevalence of induced abortion in Mexico City: Comparison of four methodologies," paper presented at the 24th Population Conference of the International Union for the Scientific Study of Population, 18-24 August, Salvador de Bahia.

Matasha, E., et al. 1998. "Sexual and reproductive health among primary and secondary school pupils in Mwanza, Tanzania: Need for intervention," AIDS Care 10(5): $571-582$.

Meekers, Dominique. 1994. "Sexual initiation and premarital childbearing in sub-Saharan Africa," Population Studies 48(1): 47-64.

Mensch, Barbara S., Judith Bruce, and Margaret E. Greene. 1998. The Uncharted Passage: Girls'Adolescence in the Developing World. New York: Population Council.

Mensch, Barbara S., Wesley H. Clark, Cynthia B. Lloyd, and Annabel S. Erulkar. 1999. "Premarital sex and school dropout in Kenya: Can schools make a difference?" Policy Research Division Working Paper no. 124. New York: Population Council. Forthcoming Studies in Family Planning.

Mensch, Barbara S. and Denise B. Kandel. 1988. "Underreporting of substance use in a national longitudinal cohort," Public Opinion Quarterly 52(1): 100-124.

National Council for Population and Development (NCPD), Central Bureau of Statistics (CBS), and Macro International. 1999. Kenya Demographic and Health Survey 1998. Calverton, MD: NCPD, CBS, and Macro International.

Population Reference Bureau. 2001. Youth in Sub-Saharan Africa: A Chartbook on Sexual Experience and Reproductive Health. Washington, D.C.: Population Reference Bureau.

Rumakom, Patchara, Philip Guest, Waranuch Chinvarasopak, Watit Utmarat, and Jiraporn Sontanakanit. 1999. Draft. "Obtaining accurate responses to sensitive questions: A comparison of two data collection techniques.” Bangkok: Population Council. 
Turner, Charles F., Heather G. Miller, and Susan M. Rogers. 1997. "Survey measurement of sexual behavior: Problems and progress," in John Bancroft (ed.), Researching Sexual Behavior: Methodological Issues. Bloomington: Indiana University Press, pp. 37-60.

Turner, Charles F., et al. 1998. "Adolescent sexual behavior, drug use, and violence: Increased reporting with computer survey technology," Science 280(5365): 867873.

Tourangeau, Roger, Lance J. Rips, and Kenneth Rasinski. 2000. The Psychology of Survey Response. Cambridge University Press.

Tourangeau, Roger and Tom W. Smith. 1996. "Asking sensitive questions: The impact of data collection mode, question format and question content," Public Opinion Quarterly 60(2): 275-304.

UNAIDS, 1998. "UNAIDS Fact Sheet on differences in HIV spread in African cities: AIDS in Africa," accessed on-line 16 June 2000 at: http://www.unaids.org/ publications/documents/epidemiology/determinants/saepap98.html

UNAIDS and WHO. 1998. "Epidemiological Fact Sheet on HIV/AIDS and sexually transmitted diseases: Kenya," accessed on-line 16 June 2000 at: http://www.who.int/emchiv/fact_sheets.html

van de Wijgert, Janneke, Nancy Padian, Stephen Shiboski, and Charles Turner. 2000. "Is audio computer-assisted self-interviewing a feasible method of surveying in Zimbabwe?” International Journal of Epidemiology 29(5): 885-890.

Williams, Mark L., et al. 2000. "A comparison of the reliability of self-reported drug use and sexual behaviors using computer-assisted versus face-to-face interviewing," AIDS Education and Prevention 12(3): 199-213. 


\section{POLICY RESEARCH DIVISION WORKING PAPERS}

Recent Back Issues

1999

*120 John Bongaarts, "The fertility impact of changes in the timing of childbearing in the developing world."

*121 James F. Phillips, Wendy L. Greene, and Elizabeth F. Jackson, "Lessons from community-based distribution of family planning in Africa."

*122 Mark R. Montgomery, "Mortality decline and the demographic response: Toward a new agenda."

*123 Mark R. Montgomery, Mary Arends-Kuenning, and Cem Mete, "The quantity-quality transition in Asia."

124 Barbara S. Mensch, Wesley H. Clark, Cynthia B. Lloyd, and Annabel S. Erulkar, "Premarital sex and school dropout in Kenya: Can schools make a difference?"

*125 John Bongaarts and Rodolfo A. Bulatao, "Completing the demographic transition."

126 Geoffrey McNicoll, "Population weights in the international order."
*127 Cynthia B. Lloyd, Carol E. Kaufman, and Paul Hewett, "The spread of primary schooling in subSaharan Africa: Implications for fertility change."

128 John B. Casterline, "The onset and pace of fertility transition: National patterns in the second half of the twentieth century."

*129 Mark R. Montgomery, Michele Gragnolati, Kathleen Burke, and Edmundo Paredes, "Measuring living standards with proxy variables."

130 Bamikale Feyisetan and John B. Casterline, "Fertility preferences and contraceptive change in developing countries."

*131 Martin Brockerhoff, "Urban growth in developing countries: A review of projections and predictions."

132 Omaima El-Gibaly, Barbara Ibrahim, Barbara S. Mensch, and Wesley H. Clark, "The decline of female circumcision in Egypt: Evidence and interpretation."

* No longer available 
133 Mary Arends-Kuenning and Sajeda Amin, "The effects of schooling incentive programs on household resource allocation in Bangladesh."

134 John Bongaarts and Charles F. Westoff, "The potential role of contraception in reducing abortion."

135 John B. Casterline and Steven W. Sinding, "Unmet need for family planning in developing countries and implications for population policy."

*136 Carol E. Kaufman, Thea de Wet, and Jonathan Stadler, "Adolescent pregnancy and parenthood in South Africa."

*137 Valerie L. Durrant and Zeba A. Sathar, "Greater investments in children through women's empowerment: A key to demographic change in Pakistan?"

138 Sajeda Amin, Alaka Malwade Basu, and Rob Stephenson, "Spatial variation in contraceptive use in Bangladesh: Looking beyond the borders."
139 Geoffrey McNicoll, "Managing population-environment systems: Problems of institutional design."

140 Barbara S. Mensch, Barbara L. Ibrahim, Susan M. Lee, and Omaima ElGibaly, "Socialization to gender roles and marriage among Egyptian adolescents."

141 John Bongaarts and Elof Johansson, "Future trends in contraception in the developing world: Prevalence and method mix."

142 Alaka Malwade Basu and Sajeda Amin, "Some preconditions for fertility decline in Bengal: History, language identity, and an openness to innovations."

143 Zeba Sathar, Cynthia B. Lloyd, Cem Mete, and Minhaj ul Haque, "Schooling opportunities for girls as a stimulus for fertility change in rural $\mathrm{Pa}$ kistan."
144 John Bongaarts, "Household size and composition in the developing world."

145 John B. Casterline, Zeba A. Sathar, and Minhaj ul Haque, "Obstacles to contraceptive use in Pakistan: A study in Punjab."
146 Zachary Zimmer, Albert I. Hermalin, and Hui-Sheng Lin, "Whose education counts? The impact of grown children's education on the physical functioning of their parents in Taiwan." 
147 Philomena Nyarko, Brian Pence, and Cornelius Debpuur, "Immunization status and child survival in rural Ghana."

148 John Bongaarts and Zachary Zimmer, "Living arrangements of older adults in the developing world: An analysis of DHS household surveys."

149 Markos Ezra, "Ecological degradation, rural poverty, and migration in Ethiopia: A contextual analysis."
150 Cynthia B. Lloyd, Sahar El Tawila, Wesley H. Clark, and Barbara S. Mensch, "Determinants of educational attainment among adolescents in Egypt: Does school quality make a difference?"

151 Barbara S. Mensch, Paul C. Hewett, and Annabel Erulkar, "The reporting of sensitive behavior among adolescents: A methodological experiment in Kenya." 